\title{
Capsicum annuum enhances L-lactate production by Lactobacillus acidophilus: Implication in curd formation
}

\author{
Smriti Sharma, Sriyans Jain, Girija N. Nair, and Srinivasan Ramachandran ${ }^{1}$ \\ Functional Genomics Unit, CSIR - Institute of Genomics and Integrative Biology, South Campus, Mathura Road, New Delhi 110025, India
}

\begin{abstract}
Lactobacillus acidophilus is commonly used lactic acid bacteria for producing fermented milk products. In general household practice, curdling is known to occur faster in the presence of red chili. Herein we analyzed the enhanced effect of red chili (Capsicum annuum) and its major component, capsaicin, on Lactobacillus acidophilus (ATCC 4356) in the production of L-lactate in de Man, Rogosa, and Sharpe medium at various temperatures $\left(15,20,25,30\right.$, and $\left.37^{\circ} \mathrm{C}\right)$. The addition of red chili showed significant increase in the amount of L-lactate produced by $L$. acidophilus compared with the control at all temperatures. Similar results were observed with addition of capsaicin alone. This was accompanied by an increase in the consumption of Dglucose. Capsazepine, a known antagonist of capsaicin, inhibited the production of L-lactate by L acidophilus in the presence of both capsaicin and red chili. Because no increase occurred in the growth of L. acidophilus in the presence of red chili, the enhanced production of L-lactate in the presence of red chili or capsaicin is due to increased metabolic activity.
\end{abstract}

Key words: Lactobacillus acidophilus, capsaicin, L-lactate, curdling

\section{INTRODUCTION}

Lactic acid bacteria are among the most important groups of acid-producing bacteria used in the food industry for the production of fermented food products such as cheese, yogurt, and sausages (Rhee et al., 2011). One of the most commonly used lactic acid bacteria is Lactobacillus acidophilus, which is preferably used as starter culture for fermentation along with Streptococcus thermophilus (Ahmed and Kanwal, 2004). Bacterial fermentation reduces the $\mathrm{pH}$ of milk by conversion of milk sugar lactose into lactic acid (Lee and Lucey, 2010). This acidification of milk (decrease in $\mathrm{pH}$ from 6.6 to 6) leads to the disruption of casein micelles, which reduces the net negative charge on casein and,

Received October 9, 2012.

Accepted March 20, 2013

${ }^{1}$ Corresponding author: ramu@igib.in hence, the electrostatic repulsion. Further decrease in the $\mathrm{pH}$ to 5 or lower causes casein to coagulate, leading to curd formation (Lucey, 2004).

In a conventional household setup, curdling of milk may be induced by adding several different curdling agents or adding a small amount of preformed curd, with subsequent incubation at warm temperature. Red chili pepper is also used to induce curdling of milk, particularly in the colder regions or during winters or when starter cultures run out (Katz, 2011). Red chili is a common spice used in many food items and also in various pharmaceutical preparations (Barceloux, 2008). Capsaicin (8-methyl- $N$-vanillyl-6-nonenamide), one of the active ingredients in red chili, is known to have several medicinal properties, such as its potential to attenuate hypertension (Yang et al., 2010) and to suppress tumor growth by inducing apoptosis (Pramanik and Srivastava, 2012). The present study was designed to elucidate the effect of red chili and its main component capsaicin in the enhanced production of L-lactate by L. acidophilus.

\section{MATERIALS AND METHODS}

\section{Chemicals, Biochemicals, and Reagents}

Capsaicin, capsazepine, and glycerol were purchased from Sigma Chemical Co. (St. Louis, MO). Red chili and toned milk containing $3 \%$ fat and $8.5 \%$ SNF were purchased from a local retail outlet and Mother Dairy (New Delhi, India), respectively. de Man, Rogosa, and Sharpe (MRS) medium, customized Columbia colistin nalidixic acid (CNA) plates with 5\% sheep blood and carbohydrate estimation kit were purchased from HiMedia Laboratories (Mumbai, India). D-Lactate and L-lactate colorimetric assay kits were procured from BioVision Inc. (Milpitas, CA). Absolute ethanol, methanol, and sodium hypochlorite used in the study were of Excela R grade and purchased from Qualigens Fine Chemicals Pvt. Ltd. (Mumbai, India).

\section{Bacterial Strain Used, Its Revival, and Maintenance of Bacterial Culture}

Lyophilized pellets of L. acidophilus were purchased from American Type Culture Collection (ATCC; Manas- 
sas, VA). The bacterial culture was revived following the ATCC guidelines. Briefly, a single bacterial pellet was suspended in $1 \mathrm{~mL}$ of sterile water. The bacterial suspension was evenly spread using sterile cotton swabs on nonselective MRS agar. The plates were incubated at $37^{\circ} \mathrm{C}$ for $48 \mathrm{~h}$ under aerobic conditions. The colonies obtained were later transferred to CNA agar containing $5 \%$ sheep blood and incubated anaerobically at $37^{\circ} \mathrm{C}$ for $48 \mathrm{~h}$. An isolated colony was inoculated in MRS broth and grown at $37^{\circ} \mathrm{C}$ with constant shaking at 200 rpm, until the optical density at a wavelength of 600 $\mathrm{nm}\left(\mathrm{OD}_{600}\right)$ reached about 0.7 (mid-logarithmic phase; Kerr and McHale, 2001). The bacterial culture, at this stage, was stored at $4^{\circ} \mathrm{C}$ until further use (Rooj et al., 2010). Pure culture was maintained by adding $30 \%$ glycerol with immediate freezing at $-80^{\circ} \mathrm{C}$, whereas growing culture was maintained by weekly transfer in MRS broth (de Man et al., 1960).

\section{Chili Samples and Treatments}

Capsicum annuum (red chili) was surface sterilized using $2 \%$ sodium hypochlorite solution. Chili was kept immersed in sodium hypochlorite solution for 2 to $3 \mathrm{~min}$, rinsed thoroughly with sterile water 3 to 4 times, and dried in laminar flow hood. For experiments with aqueous extract of chili, the appropriate amount $(400 \mathrm{mg})$ of chili was weighed, mashed, and mixed thoroughly with sterile water by vortexing. The mixture was centrifuged at $6,700 \times g$ for $10 \mathrm{~min}$. The supernatant was collected and filter sterilized using a $0.2-\mu \mathrm{m}$ filter. Capsaicin and capsazepine were dissolved in absolute ethanol and methanol, respectively, for preparing stock solutions of $500 \mathrm{mg} / \mathrm{mL}$. Toned milk with $3 \%$ fat and $8.5 \% \mathrm{SNF}$ was used in all experiments. Milk was heated to $75^{\circ} \mathrm{C}$ and then cooled to $35^{\circ} \mathrm{C}$ before adding the starter culture. Bacterial culture $\left(\mathrm{OD}_{600}=0.6-0.7\right)$ was added to milk in the ratio of $1: 5(\mathrm{vol} / \mathrm{vol})$. In control samples, no chili was added, whereas test samples contained 400 $\mathrm{mg}$ of whole chili per $10 \mathrm{~mL}$ of milk. The samples were incubated at 5 temperatures $\left(15,20,25,30\right.$, and $\left.37^{\circ} \mathrm{C}\right)$ without shaking and the time required for curdling was monitored. We noted the time of separation of whey from curd as the endpoint of curdling. Samples were analyzed in duplicate and triplicate.

\section{Analysis}

pH Measurement and Viable Cell Count. The $\mathrm{pH}$ of milk was measured at all 5 incubation temperatures $\left(15,20,25,30\right.$, and $\left.37^{\circ} \mathrm{C}\right)$ at initial and final time points in the control and test samples using a digital $\mathrm{pH}$ meter. The final time point was considered as the time of complete curd formation. Direct microscopic count was used to estimate the number of viable bacterial cells at initial and final time points. The samples were diluted 10-fold and mixed in a 1:1 ratio (vol/ vol) with $0.04 \%$ trypan blue. Viable cells were counted using a hemocytometer under $40 \times$ magnification of a compound microscope (Nikon Eclipse 80i; Nikon Corp., Tokyo, Japan).

Determination of Lactate Production and D-Glucose Consumption in MRS Broth. Initially, we determined the concentration of D-lactate and L-lactate produced by L. acidophilus at $37^{\circ} \mathrm{C}$. A significant increase in the concentration of L-lactate was observed. However, no significant difference in the concentration of D-lactate was produced at the initial and final time points. The results were in accordance with a previous study, which reported that L-lactate is produced in higher amounts by L. acidophilus in MRS medium compared with D-lactate (Juárez Tomás et al., 2003). Therefore, the amount of L-lactate produced by L. acidophilus was determined because we investigated the effects of red chili and its components on bacterial culture grown in MRS media.

Different test samples containing L. acidophilus, with any of the following combinations of crude red chili, filtered aqueous extract of red chili, pure capsaicin, pure capsazepine, filtered aqueous chili extract with capsazepine, and capsaicin with capsazepine, were analyzed for L-lactate production. Each sample had bacterial culture and MRS broth in the ratio of $1: 5$ ( $\mathrm{vol} / \mathrm{vol})$. In samples with capsaicin and capsazepine, both components were added to an equal working concentration of $5 \mathrm{mg} / \mathrm{mL}$. The effect of capsazepine was examined by adding it before addition of chili extract or capsaicin and incubated for 20 to $30 \mathrm{~min}$ at the given temperature. All incubations with bacteria, after initial mixing, were carried out without shaking at all temperatures to emulate the incubation of milk inoculated with bacterial culture for curd formation.

Control and test samples were assayed to determine the amount of L-lactate produced using a colorimetric L-lactate assay kit (BioVision Inc.) as per the manufacturer's instructions. Briefly, $50 \mu \mathrm{L}$ of test sample at 1:10 dilution in MRS broth was added to a microtiter plate. An equal volume of reaction mixture $(46 \mu \mathrm{L}$ of lactate assay buffer, $2 \mu \mathrm{L}$ of lactate probe, and $2 \mu \mathrm{L}$ of enzyme mix) was added to each sample. The samples were incubated in the dark for $30 \mathrm{~min}$ at room temperature and absorbance was measured at $570 \mathrm{~nm}$. Sterile MRS broth was used as blank. L(+)-Lactate standards (BioVision Inc.), in the range of 2 to $10 \mathrm{nmol}$, were used to generate the standard curve.

The same control and test samples were also analyzed for D-glucose consumption using a carbohydrate estimation kit (HiMedia Laboratories, Mumbai, India) as per 
the manufacturer's instructions. Briefly, $200 \mu \mathrm{L}$ of test sample at 1:100 dilution in sterile water was added to the reaction mixture containing $500 \mu \mathrm{L}$ each of 3,5-dinitrosalicylic acid (DNSA) reagent and $40 \%$ potassium sodium tartrate. The absorbance was measured at 540 nm. Glucose standards (HiMedia Laboratories), diluted to concentrations of 0.2 to $1.0 \mathrm{mg} / \mathrm{mL}$, were used to generate the standard curve. The differences in absorption of initial and final values were taken for calculating the amount of D-glucose consumed in the samples. The amount of L-lactate produced and D-glucose consumed were reported in picomoles per microliter and nanomoles per microliter of the samples, respectively.

\section{Statistical Analysis}

Experiments were performed either in duplicate or triplicate. Data are reported as mean \pm 1 standard deviation. In Figure 1, the error bars represent 95\% confidence intervals, which can be used for direct comparative assessment. Welch's Student's $t$-test was performed to test the statistical significance in all the experiments, except in the last case, where the Tukey honestly significant difference test was applied, to determine the statistical significance of differences in D-glucose consumption and L-lactate production in different treatments.

\section{RESULTS AND DISCUSSION}

The time required for curdling was monitored over a variable range of temperatures, starting from 15 to $37^{\circ} \mathrm{C}$. At 15,20 , and $25^{\circ} \mathrm{C}$, both the control and the sample containing red chili took a long time to curdle, which was about 10 to $11 \mathrm{~h}$. The time taken for curdling in samples with red chili was about an hour less compared with the control. At 30 and $37^{\circ} \mathrm{C}$, the time taken for curdling, without chili, was 9 and $6.5 \mathrm{~h}$, respectively. Addition of red chili decreased the curdling time to 8 and $6 \mathrm{~h}$ at 30 and $37^{\circ} \mathrm{C}$, respectively. The results showed that the time required for curdling was decreased in the presence of red chili and this effect was observed even at lower incubation temperatures. These results indicate that addition of red chili had a greater influence on the time taken for curdling at lower temperatures compared with that at $37^{\circ} \mathrm{C}$. It is possible that because the optimal growth temperature range for L. acidophilus is 35 to $38^{\circ} \mathrm{C}$ (Zamfir and Grosu-Tudor, 2009), the difference in time taken for curdling at $37^{\circ} \mathrm{C}$ in the presence versus absence of chili is small compared with the bacteria grown at lower temperatures.

Because curdling is dependent on the reduction in the $\mathrm{pH}$ of milk (Lee and Lucey, 2010), we measured the $\mathrm{pH}$ of samples before and after curdling. Incubation of milk with bacterial culture at higher temperatures showed a sharp decrease in the $\mathrm{pH}$ of milk compared with incubation at lower temperatures in both controls and test samples with red chili (Figure 1). The initial average $\mathrm{pH}$ of milk was 6.22 . We observed a significant difference in $\mathrm{pH}$ in the presence of chili compared with controls at all temperatures $(P<0.01)$. The significant difference was also apparent in the $95 \%$ confidence intervals at all temperatures between control and test samples.

Because the increased acidity of milk during curd formation is the result of lactic acid produced by bacterial fermentation (Lee and Lucey, 2010), we determined the amount of lactic acid produced in our samples. Under normal growth conditions, L. acidophilus is known to produce D-lactate. However, when L. acidophilus is grown in MRS medium, L-lactate is mainly produced (Juárez Tomás et al., 2003). To confirm, we assayed the samples in initial experiments for the amount of D-lactate and L-lactate produced at $37^{\circ} \mathrm{C}$. No detectable amount of D-lactate was produced in the control samples, whereas a very small amount of D-lactate was produced in test samples with red chili (Appendix Table A1).

We therefore initially determined the amount of Llactate produced in control and test samples using red chili at different incubation temperatures $(15,20,25$, 30 , and $37^{\circ} \mathrm{C}$ ) in MRS broth. The results are shown in Figure 2. We observed a significant increase in the amount of L-lactate produced in test samples contain-

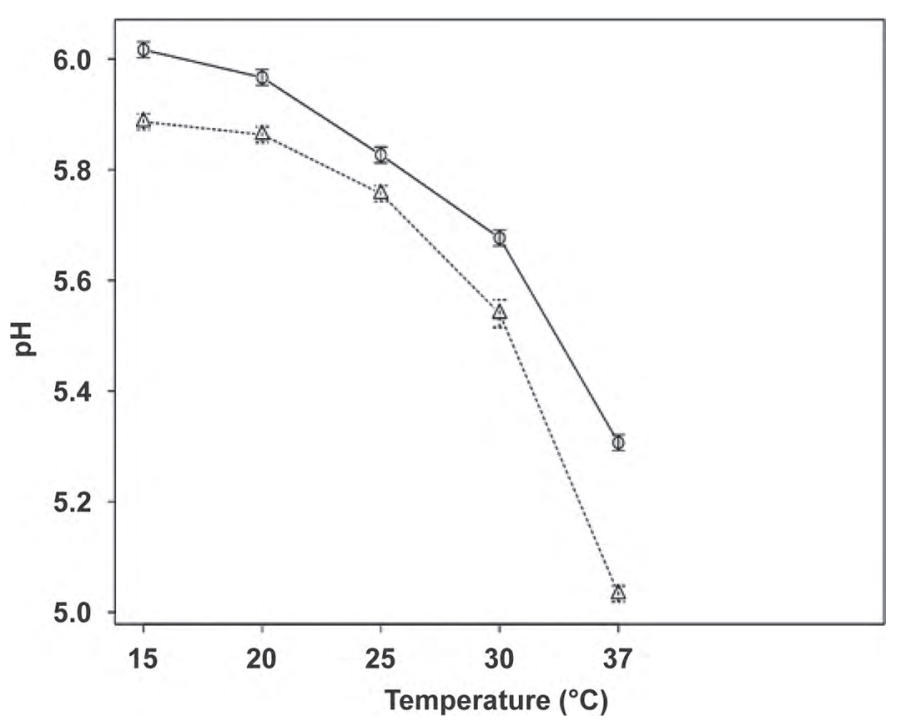

Figure 1. pH measurement in control (without red chili; - $\bigcirc-$ ) and test (with red chili; " $\Delta^{*}$ ) samples after complete curdling of milk over a variable temperature range of $15,20,25,30$, and $37^{\circ} \mathrm{C}$. Each point is the mean of triplicate analyses. The bars at each point represent $95 \%$ CI. 


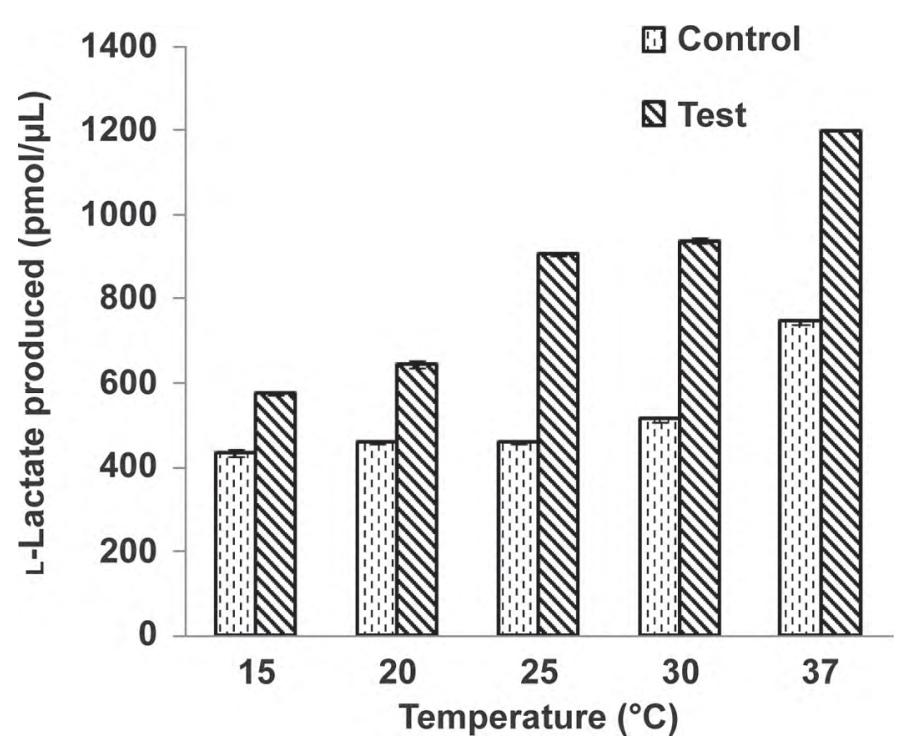

Figure 2. Amount of L-lactate produced in control (without red chili) and test (with red chili) samples, determined in de Man, Rogosa, and Sharpe (MRS) broth at different temperatures. The error bars at each point represent $1 \mathrm{SD}$. We observed the final time point at $11 \mathrm{~h}$ for $15^{\circ} \mathrm{C}, 10 \mathrm{~h}$ for $20^{\circ} \mathrm{C}, 9 \mathrm{~h}$ for $25^{\circ} \mathrm{C}, 8 \mathrm{~h}$ for $30^{\circ} \mathrm{C}$, and $6 \mathrm{~h}$ for $37^{\circ} \mathrm{C}$.

ing red chili compared with controls at all incubation temperatures $(P<0.01)$. However, the enhanced effect of red chili on L-lactate production was more profound at incubation temperatures of $25^{\circ} \mathrm{C}$ and above.

The increase in the amount of L-lactate produced by L. acidophilus could be attributed to 1 of the 2 hypotheses: either addition of chili enhances the growth of bacteria, resulting in an increased number of viable bacterial cells, with consequent higher production of L-lactate or red chili influences bacterial metabolism, leading to increased release of L-lactate. In an attempt to examine the former hypothesis, we directly counted the number of viable bacterial cells in control and test samples at initial and final time points incubated at 25, 30 , and $37^{\circ} \mathrm{C}$ for the same time periods, using trypan blue stained samples under the microscope. The viable cells were visible as transparent rods, whereas the dead cells absorbed trypan blue stain and appeared blue in color. The results are shown in Table 1. Except in the case of the control at $37^{\circ} \mathrm{C}$, we did not observe a significant increase in the number of viable bacteria either in the presence or in the absence of chili at different temperatures. This is perhaps due to the lower-thanoptimum growth temperature for L. acidophilus. Even the increased growth observed at $37^{\circ} \mathrm{C}$ in one set of experiments was not consistent. This trend may be attributed to the fact that in our experiments, incubation with bacteria after initial mixing was carried out without shaking at all temperatures to emulate the standing incubation of milk inoculated with bacterial culture for curd formation. Furthermore, we did not observe any morphological difference in bacterial cell shapes between control and test sets of samples. Therefore, the increased production of L-lactate by L. acidophilus does not appear to be due to increased growth rate in the presence of red chili.

Next, we investigated the effect filtered aqueous extract of red chili on L-lactate production by $L$. acidophilus at temperatures of 25,30 , and $37^{\circ} \mathrm{C}$, as the enhancement effect was prominently observable from $25^{\circ} \mathrm{C}$ onwards. The results are shown in Appendix Figure A1. The enhancement effect was consistent, as observed using red chili itself. Subsequently, we chose to investigate the enhancement effects of filtered aqueous extract of red chili and capsaicin on L-lactate production at $30^{\circ} \mathrm{C}$, which is $5^{\circ} \mathrm{C}$ less than the optimal growth temperature range in the present context.

Capsaicin, an active ingredient of red chili (responsible for its pungency), is a naturally occurring vanilloid. Its consumption is linked with increased metabolic rate and core body temperature (Kobayashi et al., 1998; Mahmmoud, 2008). Capsazepine is a synthetic analog of capsaicin, which is known to competitively inhibit the effects of capsaicin (Szallasi and Blumberg, 1999). Therefore, we next investigated the effect of capsaicin

Table 1. Number of viable cells counted in control (without chili) and test samples (with red chili) at initial and final time points in de Man, Rogosa, and Sharpe (MRS) broth, incubated at different temperatures ${ }^{1}$

\begin{tabular}{|c|c|c|c|c|c|c|c|}
\hline \multirow{2}{*}{$\begin{array}{l}\text { Temperature } \\
\left({ }^{\circ} \mathrm{C}\right)\end{array}$} & \multirow{2}{*}{ Sample } & \multicolumn{6}{|c|}{ No. of viable cells $\left(\times 10^{6}\right.$ cells $\left./ \mathrm{mL}\right)$} \\
\hline & & \multicolumn{3}{|c|}{ Experiment 1 (in duplicate) } & \multicolumn{3}{|c|}{ Experiment 2 (in triplicate) } \\
\hline \multirow[t]{2}{*}{25} & Control & $1.9,2.1$ & $1.2,1.8$ & 0.33 & $2.5 \pm 0.35$ & $2.6 \pm 0.31$ & 0.36 \\
\hline & Test & $1.7,1.9$ & $1,1.1$ & 0.04 & $2.4 \pm 0.25$ & $2.3 \pm 0.2$ & 0.26 \\
\hline 30 & Control & $2.3,2.1$ & $1.8,2$ & 0.17 & $2.4 \pm 0.27$ & $2.2 \pm 0.15$ & 0.2 \\
\hline 37 & Test & $1.8,2.4$ & $1.2,1.4$ & 0.2 & $2.2 \pm 0.15$ & $2.1 \pm 0.42$ & 0.45 \\
\hline
\end{tabular}

${ }^{1}$ In experiment 1 , the duplicate values are represented, whereas in experiment 2 , the values represent mean \pm 1 SD of triplicate experiments. 
on L-lactate production by L. acidophilus and whether the enhanced effects of capsaicin could be annulled by capsazepine. The amount of L-lactate produced in the control and test samples using filtered aqueous extract of red chili, pure capsaicin, pure capsazepine, a combination of filtered aqueous extract of red chili and capsazepine, and a combination of capsaicin and capsazepine were determined. The results of these experiments are shown in Figure 3.

We observed enhancement of L-lactate production by L. acidophilus in the presence of capsaicin, which was similar to that observed from filtered aqueous extract of red chili (Figure 3). This enhancement effect was inhibited in the presence of capsazepine, where the amount of L-lactate produced was lower than that of the control. The effect of capsazepine alone on L-lactate production was closer to that of the control, showing slightly enhanced effect but far less than either filtered aqueous extract of red chili or capsaicin. The data for L-lactate production and D-glucose consumption were analyzed for statistically significant differences using the Tukey honestly significant difference test. A significant increase was observed in the amount of L-lactate produced in both cases in the presence of filtered aqueous extract of red chili and capsaicin compared with the control (adjusted $P<0.01$; Appendix Table A2). Also, in the presence of capsazepine alone, a significant amount of L-lactate was produced (adjusted $P<$ 0.01 ), indicating that capsazepine alone does not in-

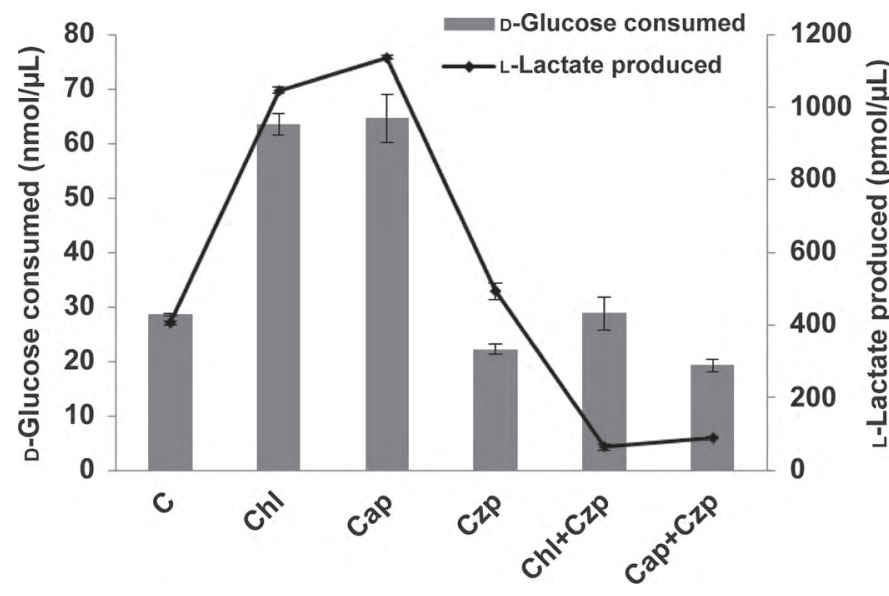

Figure 3. Amount of D-glucose consumed $(\mathrm{nmol} / \mu \mathrm{L})$ and L-lactate produced $(\mathrm{pmol} / \mu \mathrm{L})$ at $30^{\circ} \mathrm{C}$ in control and test samples with different treatments, determined in de Man, Rogosa, and Sharpe (MRS) broth. The histograms (y-axis scale on the left) show the amount of D-glucose consumed. The curves (y-axis scale on the right) indicate the amount of L-lactate produced. The error bars at each point represent $1 \mathrm{SD}$. $\mathrm{C}=$ control without chili; $\mathrm{Chl}=$ aqueous extract of red chili alone; Cap = capsaicin alone; Czp = capsazepine alone; $\mathrm{Chl}+\mathrm{Czp}=$ combination of aqueous extract of red chili with capsazepine; Cap+Czp = combination of capsaicin with capsazepine. The final time point was observed at $8 \mathrm{~h}$. hibit L-lactate production by L. acidophilus. In parallel, consumption of D-glucose was significantly enhanced in both cases in the presence of filtered aqueous extract of red chili and capsaicin (Figure 3). L-Lactate production was severely inhibited in samples containing capsazepine and either capsaicin or filtered aqueous extract of red chili (adjusted $P<0.01$; Appendix Table A2). However, D-glucose was still consumed, similar to consumption in the control, indicating the ongoing metabolic activity. It has been reported that capsaicin activates ion channels of plasma membrane and capsazepine is a competitive antagonist (Bevan et al., 1992). These observations suggest that the enhancement of L-lactate production due to capsaicin is likely at the level of L-lactate export from the bacteria.

Therefore, it is evident that, in the presence of filtered aqueous extract of red chili or its active ingredient capsaicin, the enhancement in L-lactate production is due to the enhanced metabolic activity of $L$. acidophilus. We were intrigued by the effect of capsaicin on enhancement of L-lactate production with accompanied increase in D-glucose consumption by $L$. acidophilus, considering that capsaicin is insoluble in water. However, the effect we observed was reproducible and this may perhaps be due to the interaction of surface receptors of $L$. acidophilus with capsaicin. In the presence of red chili, capsaicin may be present as an emulsion allowing favorable interaction with bacterial cell membranes.

Capsaicin has also been shown to stimulate uncoupled ATP hydrolysis, which is likely of significance to modulate thermogenesis (Mahmmoud, 2008). Many studies in the medical literature have linked the consumption of chili-enriched meals with increased energy expenditure and oxidation of fats (Diepvens et al., 2007). In humans, capsaicin and its nonpungent analogs have been shown to act through surface transient receptor potential vanilloid type 1 (TrpV1) receptors, which consequently affect the basal metabolic rate by increasing energy metabolism (Inoue et al., 2007). Our efforts in identifying homologs of TRPV1 receptors in L. acidophilus through BLAST (Altschul et al., 1990) searches revealed ABC transporters with weak similarity. In the future, the detailed mechanistic action of capsaicin on L. acidophilus receptors remains to be unraveled.

\section{ACKNOWLEDGMENTS}

The authors acknowledge the Council of Scientific and Industrial Research (CSIR, New Delhi, India) for funding. We also thank Rakesh Sharma (CSIR) for the stimulating discussions, Bhanwar Lal Puniya (CSIR) for helping with the statistical analysis, and A. Ram- 
achandran (International Institute of Health Management Research, Delhi, India) for sharing the details of household practice of enhanced curdling using red chili during winters. The present study was financially supported by the Council for Scientific and Industrial Research (project code EXP 004). The funding source had no role in the study design; collection, analysis, and interpretation of data; writing of the manuscript; or the decision to submit the article for publication.

\section{REFERENCES}

Ahmed, T., and R. Kanwal. 2004. Biochemical characterization of lactic acid producing bacteria and preparation of camel milk cheese by using starter culture. Pakistan Vet. J. 24:87-91.

Altschul, S. F., W. Gish, W. Miller, E. W. Myers, and D. J. Lipman. 1990. Basic local alignment search tool. J. Mol. Biol. 215:403-410.

Barceloux, D. G. 2008. Pepper and capsaicin (Capsicum and Piper species). Pages 71-73 in Medical Toxicology of Natural Substances: Foods, Fungi, Medicinal Herbs, Plants and Venomous Animals. John Wiley and Sons Inc., Hoboken, NJ.

Bevan, S., S. Hothi, G. Hughes, I. F. James, H. P. Rang, K. Shah, C. S. J. Walpole, and J. C. Yeats. 1992. Capsazepine: A competitive antagonist of the sensory neurone excitant capsaicin. Br. J. Pharmacol. 107:544-552.

de Man, J. C., M. Rogosa, and M. E. Sharpe. 1960. A medium for cultivation of lactobacilli. J. Appl. Microbiol. 23:130-135.

Diepvens, K., K. R. Westerterp, and M. S. Westerterp-Plantenga. 2007. Obesity and thermogenesis related to the consumption of caffeine, ephedrine, capsaicin, and green tea. Am. J. Physiol. Regul. Integr. Comp. Physiol. 292:R77-R85.

Inoue, N., Y. Matsunaga, H. Satoh, and M. Takahashi. 2007. Enhanced energy expenditure and fat oxidation in humans with high BMI scores by the ingestion of novel and non-pungent capsaicin analogues (capsinoids). Biosci. Biotechnol. Biochem. 71:380-389.

Juárez Tomás, M. S., V. S. Ocaña, B. Wiese, and M. E. Nader-Macías. 2003. Growth and lactic acid production by vaginal Lactobacillus acidophilus CRL 1259, and inhibition of uropathogenic Escherichia coli. J. Med. Microbiol. 52:1117-1124.

Katz, S. E. 2011. The Art of Fermentation. Chelsea Green Publishing, White River Junction, VT.

Kerr, T. J., and B. B. McHale. 2001. Applications in General Microbiology: A Laboratory Manual. 6th ed. Hunter Textbooks, WinstonSalem, NC.

Kobayashi, A., T. Osaka, Y. Namba, S. Inoue, T. H. Lee, and S. Kimura. 1998 Capsaicin activates heat loss and heat production simultaneously and independently in rats. Am. J. Physiol. Regul. Integr. Comp. Physiol. 275:R92-R98.

Lee, W. J., and J. A. Lucey. 2010. Formation and physical properties of yogurt. Asian-australas. J. Anim. Sci. 23:1127-1136.

Lucey, J. A. 2004. Formation, structural properties and rheology of acid coagulated milk gels. Pages $105-122$ in Cheese: Chemistry, Physics and Microbiology, Volume 1: General Aspects. 3rd ed. P. F. Fox, P. L. H. McSweeney, T. M. Cogan, and T. P. Guinee, ed. Elsevier Academic Press, London, UK.

Mahmmoud, Y. A. 2008. Capsaicin stimulates uncoupled ATP hydrolysis by the sarcoplasmic reticulum calcium pump . J. Biol. Chem. 283:21418-21426.

Pramanik, K. C., and S. K. Srivastava. 2012. Apoptosis signal-regulating kinase 1-thioredoxin complex dissociation by capsaicin causes pancreatic tumor growth suppression by inducing apoptosis. Antioxid. Redox Signal. 17:1417-1432.

Rhee, S. J., J.-E. Lee, and C.-H. Lee. 2011. Importance of lactic acid bacteria in Asian fermented foods. Microb. Cell Fact. 10(Suppl. 1):S5

Rooj, A. K., Y. Kimura, and R. K. Buddington. 2010. Metabolites produced by probiotic lactobacilli rapidly increase glucose uptake by CaCo-2 cells. BMC Microbiol. 10:16.

Szallasi, A., and P. M. Blumberg. 1999. Vanilloid (capsaicin) receptors and mechanisms. Pharmacol. Rev. 51:159-212.

Yang, D., Z. Luo, S. Ma, W. T. Wong, L. Ma, J. Zhong, H. He, Z. Zhao, T. Cao, Z. Yan, D. Liu, W. J. Arendshorst, Y. Huang, M. Tepel, and Z. Zhu. 2010. Activation of TRPV1 by dietary capsaicin improves endothelium-dependent vasorelaxation and prevents hypertension. Cell Metab. 12:130-141.

Zamfir, M., and S. Grosu-Tudor. 2009. Impact of stress conditions on the growth of Lactobacillus acidophilus IBB 801 and production of acidophilin 801. J. Gen. Appl. Microbiol. 55:277-282. 


\section{APPENDIX}

Table A1. Amount of D-lactate produced in control and test samples (mean $\pm \mathrm{SD}$ ), using red chili, when grown in de Man, Rogosa, and Sharpe (MRS) broth at $37^{\circ} \mathrm{C}$

\begin{tabular}{lc}
\hline Sample & $\begin{array}{c}\text { D-Lactate produced during } \\
\text { incubation }(\mathrm{pmol} / \mu \mathrm{L})\end{array}$ \\
\hline Control (without red chili) & 0 \\
Test (with red chili) & $14 \pm 2.24$ \\
\hline
\end{tabular}

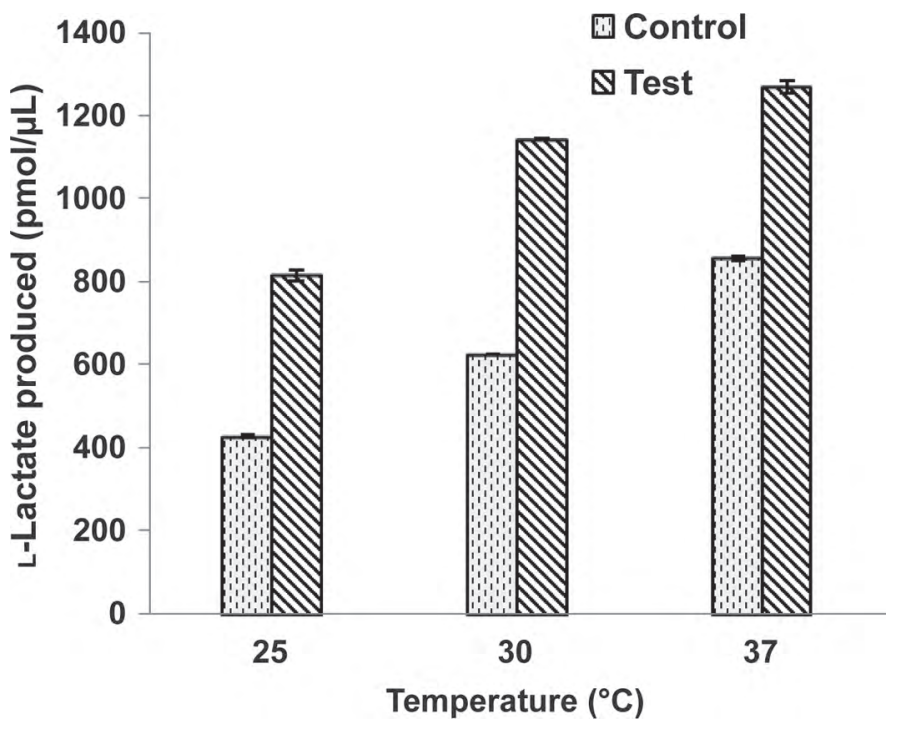

Figure A1. Amount of L-lactate produced in control (without filtered aqueous extract of red chili) and test (with filtered aqueous extract of red chili) samples during incubation at different temperatures determined in de Man, Rogosa, and Sharpe broth. The error bars at each point represent $1 \mathrm{SD}$. We observed the final time point at $9 \mathrm{~h}$ for $25^{\circ} \mathrm{C}, 8 \mathrm{~h}$ for $30^{\circ} \mathrm{C}$ and $6 \mathrm{~h}$ for $37^{\circ} \mathrm{C}$.

Table A2. The results of the Tukey honestly significant difference test used for the amount of L-lactate produced and D-glucose consumed at $30^{\circ} \mathrm{C}$ in different test samples as compared with control

\begin{tabular}{lcc}
\hline & \multicolumn{2}{c}{ Adjusted $P$-value } \\
\cline { 2 - 3 } Sample & $\begin{array}{l}\text { L-Lactate } \\
\text { produced }\end{array}$ & $\begin{array}{c}\text { D-Glucose } \\
\text { consumed }\end{array}$ \\
\hline Aqueous extract of red chili $(\mathrm{Chl})$ & $<0.01$ & $<0.01$ \\
Capsaicin (Cap) & $<0.01$ & $<0.01$ \\
Capsazepine (Czp) & $<0.01$ & 0.21 \\
Aqueous extract of red chili + capsazepine (Chl + Czp) & $<0.01$ & 0.999 \\
Capsaicin + capsazepine (Cap + Czp) & $<0.01$ & 0.054 \\
\hline
\end{tabular}

